\title{
EVALUATION OF THE PROMISING COTTON LINE (CB $58 \times$ Giza 90) IN SOUTH EGYPT
}

\author{
SHAKER, S.A. and H.B. E. ABO-TOUR \\ Cotton Research Institute, Agricultural Research center, Giza, Egypt.
}

(Manuscript received 19 December 2018)

\begin{abstract}
$\mathrm{T}$ he promising cotton line CB 58 x Giza 90 was grown compared with Giza 90 and Giza 95 cultivars and a new promising line at four locations during 2016 and 2017 seasons (eight environments) in South Egypt. The randomized complete block design with four replications was used at each location. The characters studied were seed cotton yield, lint yield, boll weight, lint percentage, seed index, lint index, fiber length, length uniformity ratio, micronaire reading and fiber strength. Significant differences were detected among genotypes for all traits except boll weight. In addition, significant differences were found among environments for all characters. Genotype by environment interaction was significant for all studied characters except boll weight, seed index and lint index. The promising line CB $58 \times$ Giza 90 surpassed the commercial cultivars for yield traits but, it did not differ significantly with the promising line $[((G .83 \times$ G.80) $\times$ G.89) $\times$ Australian] for lint percentage. The promising cotton line $\mathrm{CB} 58 \times$ Giza 90 was equal to the commercial cultivars for length uniformity ratio. The commercial cultivars recorded the highest values for seed and lint index. Giza 95 cultivar recorded the best values for fiber characters. The promising line CB $58 \times$ Giza 90 produced the highest values for most characters at sohag location where it surpassed the commercial cultivars for yield characters and with no significant difference for fiber length. Therefore, it seems necessary to continue evaluating the new cotton genotypes at several locations over an adequate number of years before recommending a given variety for a certain location. Giza 90 cultivar was considered stable across a wide range of environments. Giza 95 cultivar was less sensitive to environmental changes. So it could be more adapted to poor- yielding environments. The genotypes, Giza 90 and the two lines had more general adaptability to all environments.
\end{abstract}

Key words: Evaluate adaptability, stability and cotton.

\section{INTRODUCTION}

Cotton yield and its components are of great interest to the cotton producer. Lint length, fineness and fiber strength are the most important factors determining cotton quality, and hence affecting markedly the spinning value of raw cotton, and its performance in processing and product quality textile wet processing is one of the most polluting industrial processes.

Many of workers studied the performance of cotton varieties under different environments. Hassan et al. (2006) showed that the effect of genotype, year, location, and the interaction among them were highly significant for yield and most yield components. Also, genotype $\times$ year and genotype $\times$ location were significant for 
$2.5 \%$ span length. The second order interaction was insignificant for all fiber properties. Hassan et al. (2012) found that the effects of each of genotypes, locations and years varied significantly in all studied traits. Also, the effect of location $x$ year interaction was highly significant for all studied characters. The first order interaction genotype $x$ location was highly significant for all characters except boll weight, lint percentage and seed index, while the effect of genotypes $x$ years interaction was significant for all characters except lint percentage and seed index. Genotype $x$ year $x$ location was highly significant for all characters except seed index. Nour et al. (2012) found that the effects of environment and genotype by environment interaction were significant for cotton yield, boll weight, lint percentage, seed index, lint index, fiber length and strength ( $\mathrm{g} /$ tex), micronaire reading, length uniformity ratio and fiber elongation while, the effect of genotype was significant for the previous traits except, length uniformity index and fiber elongation. Hassan et al. (2014) found highly significant differences between genotypes, locations, seasons and the interaction between locations by seasons were obtained for yield and yield components traits. The effect of the interaction between genotypes by locations, genotypes by years and the second order interaction were highly significant for seed cotton and lint yields (kentar/faddan), boll weight, lint percentage, seed index and lint index.

Gul et al. (2014). cleared that effects of genotypes, environments and genotype $x$ environment interaction were significant for seed cotton yield.

The genotype by environment (GE) interaction detected different patterns of response among the genotypes across environments. Many investigators studied the genotype $x$ environment interaction effect on cotton yield and fiber quality. They found significant differences of (GE) for most characters. (Rahomah et al., 2008; Abdel Salam et al., 2014 and Pretorius et al., 2015). Gibely et al. (2015) studied yield and some of its components i.e. 50 bolls weight, cotton yield and lint percentage. They observed significant mean squares for genotypes, environments and genotype by environment interaction for all studied characters. Results showed that the promising cross had the highest yield potential across locations. Phenotypic stability for $F_{5} 1138$ /2012 and $F_{6} 1165$ /2012 were stable for all studied characters, except lint percentage. Genotypic stability analysis cleared that genotypes differed in the estimate $(\lambda)$, while the assaying (ai) didn't differ from ai $=0$ which may suggest the relatively unpredictable component of genotype by environment interaction variance that may be more important than the other components. El- Ganayny (2017). evaluated stability parameters for some Egyptian cotton cultivars under 14 environments (seven locations and two years) and found that year effect was significant for cotton yield, boll weight, seed and lint index, fiber length, length 
uniformity ratio and fiber strength ( $\mathrm{g} / \mathrm{tex}$ ) but not for lint percentage and micromere reading. Location, year $\mathrm{x}$ location and genotype $\mathrm{x}$ location were significant for all characters except for fiber length and length uniformity ratio. Genotypes and genotypes $x$ years were significant for all characters. The second order interaction ( $G$ $x Y x L$ ) was significant for all characters except fiber length. The cultivars Giza 87 and Giza 92 and Giza 96 were high yielders, high stable and adapted but, Giza 94 was low adapted for all environments. Shaker (2017) found that seed cotton and lint yields, boll weight, lint percentage, seed and lint index, fiber length and fiber strength, micronaire reading and length uniformity ratio showed significant mean squares for genotypes, environments and genotype by environment interaction. The phenotypic stability showed that the cultivars Giza 88, Giza 92 and Giza 96 were moderately stable for cotton yield and most yield component characters. Giza 94 was moderately stable for boll weight and lint percentage. Giza 88 was stable for fiber length. Also, Giza 86, Giza 94 and Giza 96 were stable for length uniformity ratio.

The aim of this study was to evaluate the new promising cotton line CB $58 \mathrm{x}$ Giza 90 compared with G.90, G.95 cultivars and a promising line $[((\mathrm{G} .83 \times \mathrm{G} .80) \times$ G.89) $\times$ Australian]at four locations in South Egypt in order to identify the suitable location for growing this line.

\section{MATERIALS AND METHODS}

Four Egyptian cotton genotypes viz Giza 90, Giza 95 cultivars and two new advanced F12 lines, [(G.83 × G.80) x G.89] x Australian and CB 58 × G.90 were grown at four locations in Upper Egypt (El-Fayoum, Bani-Suef, Assiut and Sohag) in the two successive seasons, 2016 and 2017. Data of yield and yield components of the studied genotypes were obtained from the yield conducted by the Regional Evaluation Research Section of the Cotton Research Institute. The experimental design was a randomized complete block with four replications at each environment. The plot size was $62.4 \mathrm{~m}^{2}$ containing 12 ridges of eight meters long and $65 \mathrm{~cm}$ wide. Distance between hills was $25 \mathrm{~cm}$ apart and each hill was thinned to two plants per hill after six weeks. Cultural practices were carried out as recommended in cotton fields. Data were collected for the following traits:

\section{1- Yield and yield components:}

- Seed cotton yield, SCY: determined as weight of seed cotton yield per plot and converted to kentar per feddan $(\mathrm{k} / \mathrm{f})$, kentar $=157.5 \mathrm{~kg}$ and feddan $=4200 \mathrm{~m}^{2}$

- Lint cotton yield, LY : calculated as: weight of seed cotton yield $\times$ lint percentage as kentar per feddan $(\mathrm{k} / \mathrm{f})$, kentar $=50 \mathrm{k.g}$.

A random sample of 50 bolls was harvested from each plot and used to obtain plot mean values for: 
a- Boll weight in grams, BW: the average weight of 50 bolls in grams.

b- Lint percentage, LP: ratio of lint weight to seed cotton weight in the sample expressed as percentage.

c- Seed index, SI: weight of 100 seeds in grams.

d- Lint index, LI: the weight of lint produced by 100 seeds in grams:

$$
- \text { Lint index }=\frac{\text { SI } \times \text { L.P }}{100-\text { L. } P} \times 100
$$

\section{2- Methods of testing cotton fiber properties:}

Samples of lint cotton from each genotype at each location were tested at the laboratories of the Cotton Technology Research Division, Cotton Research Institute at Giza to determine fiber quality properties, under controlled conditions of $65 \pm 2 \%$ of relative humidity and $20 \pm 2 \mathrm{C}^{\circ}$ temperature. Fiber properties measured by HVI (High Volume Instrument) according to A.S.T.M. D-4605-(1986) and D-1776 (1998) were:

a- $\quad$ Fiber length, FL (upper half mean $\mathrm{mm}$ ).

b- $\quad$ Length uniformity ratio, LUR.\%.

c- $\quad$ Fiber strength, FS ( $\mathrm{g} /$ tex).

d- Micronaire reading, MR.

\section{Statistical analysis:}

Analysis of variance was done according to Snedecor and Cochran (1989) for each location. Combined analysis for all regions was performed on all the studied traits as outlined by McIntosh (1983), Differences between means were compared by using the Least Significant Differences (L.S.D.) test as given by Steel and Torrie (1980). Homogeneity test of variances (Bartlett test) was used according to procedures reported by Bailey (1994). The statistical analysis for stability was carried out according to the method described by Eberhart and Russell (1966), to determine the parameters of regression coefficient (bi) and mean squares of deviation from regression $\left(S^{2} d\right)$ for each genotype were estimated. Pooled error in the regression analysis of variance was used to test whether each deviation mean square was significantly different from zero. Hence, the definition of the stable genotype will be the one with high mean yield, $b=1.0$ and $\mathrm{S}^{2} \mathrm{~d}=0$.

a) The regression coefficient (bi) which is the regression of the performance of each genotype under different environments on the environmental mean over all genotypes, is estimated as follows:

Where: 


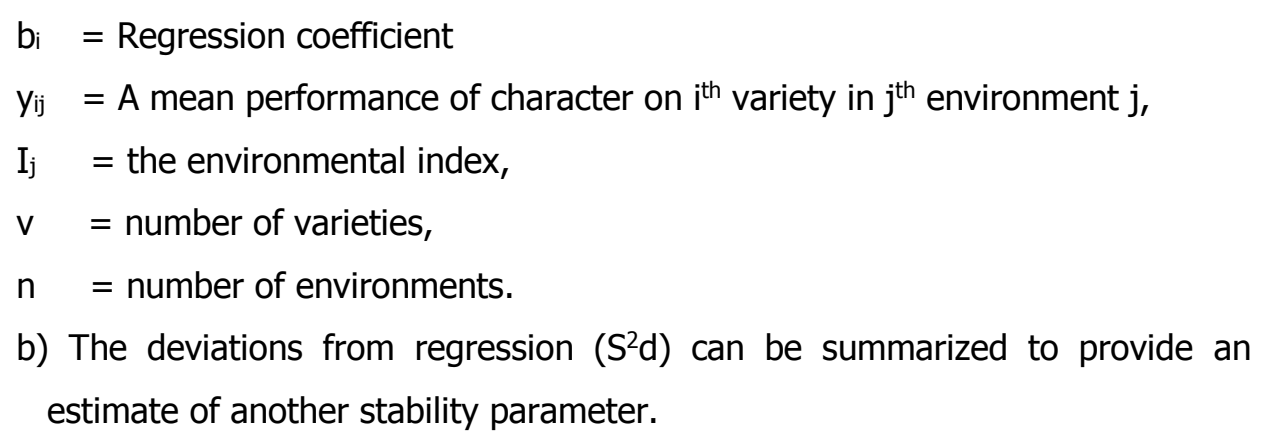

$$
\begin{aligned}
& \mathrm{S}^{2} \mathrm{~d}_{\mathrm{i}}=\left[\sum_{\mathrm{j}} \delta_{\mathrm{ij}}^{2} / \mathrm{n}-2\right]-\mathrm{S}^{2} \mathrm{e} / \mathrm{r}, \\
& \sum_{\mathrm{j}} \delta_{\mathrm{ij}}^{2}=\left[\sum_{\mathrm{j}} \mathrm{y}_{\mathrm{ij}}^{2}-\frac{\mathrm{y}_{\mathrm{i}}^{2}}{\mathrm{n}}\right]-\left[\sum_{\mathrm{j}} \mathrm{y}_{\mathrm{ij}} \mathrm{I}_{\mathrm{j}}\right]^{2} / \sum_{\mathrm{j}} \mathrm{I}_{\mathrm{j}}^{2} .
\end{aligned}
$$

$S^{2} d_{i}=$ deviations from regression of each variety,

$\mathrm{S}^{2} \mathrm{e} / \mathrm{r}=$ the estimate of pooled error,

$Y_{i}=$ total of the $i^{\text {th }}$ variety of all environments.

\section{RESULTS AND DISCUSSION}

The results in this investigation included evaluation of the promising line CB 58 x G.90 as compared with the two Egyptian cotton cultivars G.90, G.95 and a promising line $[((G .83 \times$ G. 80) $\times$ G. 89) $\times$ Australian] grown at four locations in the two successive seasons 2016 and 2017 in South Egypt.

The combined analysis of year, location, genotype and their interactions are shown in table (1). The combined analysis showed that genotypes were significant by different for yield, yield components and all fiber properties except boll weight.

With respect to effect of environments, it can be noticed that all studied traits were significantly affected; also, the effect of the interaction between genotypes and environments were significant for all studied traits except boll weight, seed index and lint index.

The results suggest that comparisons among these cotton genotypes for the studied traits should be independently estimated at each sub region over several years. These results confirm the findings of Hassan et al. (2006), Badr (2003) and Hassan et al. (2012), who reported that genotypes, locations, years and their interactions were significant for some yield components and fiber properties. 
Table 1. Mean squares of the studied traits for four Egyptian cotton genotypes grown at eight environments (four locations in the two years; 2016 and 2017).

\begin{tabular}{|c|c|c|c|c|c|c|c|c|c|c|c|}
\hline SOV & $\mathrm{df}$ & SCY & LY & BW & LP & SI & LI & $\mathrm{FL}$ & UR & $\mathrm{FS}$ & MR \\
\hline $\begin{array}{l}\text { Environments } \\
\text { (E) }\end{array}$ & 7 & $90.57 * *$ & $136.397 * *$ & $0.66181 * *$ & $25.0564 * *$ & $8.7133 * *$ & $3.2633 * *$ & $22.8592 * *$ & $11.1525 * *$ & $26.104 * *$ & $0.99835 * *$ \\
\hline Error (a) & 24 & 2.451 & 4.11 & 0.03319 & 1.4838 & 0.4617 & 0.2948 & 1.24 & 1.76 & 0.84 & 0.08 \\
\hline $\begin{array}{c}\text { Genotypes } \\
\text { (G) }\end{array}$ & 3 & $11.343 * *$ & $21.546 * *$ & 0.04924 & $22.0962 * *$ & $2.6187^{* *}$ & $1.2238 *$ & $3.4914 * *$ & $3.671 * *$ & $25.333 * *$ & $0.35719 * *$ \\
\hline$G \times E$ & 21 & $2.782 * *$ & $4.468 * *$ & 0.04502 & $1.9625^{* *}$ & 0.5416 & 0.255 & $1.2044 * *$ & $1.4875^{*}$ & $21.857 * *$ & $0.06356 *$ \\
\hline Error (b) & 72 & 0.828 & 1.36 & 0.02736 & 0.5086 & 0.6003 & 0.3047 & 0.45 & 0.86 & 0.64 & 0.03 \\
\hline $\begin{array}{c}\text { Environments } \\
\text { (GxE) }\end{array}$ & 72 & 24.728 & - & - & - & - & - & - & - & - & - \\
\hline E linear & 1 & 633.99 & - & - & - & - & - & - & - & - & - \\
\hline $\mathrm{G} \times \mathrm{E}$ linear & 3 & 2.648 & - & - & - & - & - & - & - & - & - \\
\hline Pooled dev. & 24 & 2.104 & - & - & - & - & - & - & - & - & - \\
\hline Pooled error & 96 & 1.232 & - & - & - & - & - & - & - & - & - \\
\hline
\end{tabular}

** Significant at the 0.05 and 0.01 probability levels, respectively. 


\section{Effect of environments on some economic traits of four Egyptian cotton genotypes:}

Table (2) shows the average values of studied traits as affected by different environments. The data indicated that the average values of seed cotton yield and lint cotton yield $(k / f)$ of all environments were significantly different. The highest values were obtained from genotypes grown at Sohag region in the second season and BaniSuef in the first season. Assuit region in the two seasons and El- Fayom in the second season produced the highest values of boll weight. Bani- Suef and El- Fayoum locations produced the highest lint percentage in the second season. Seed index and lint index surpassed significantly at Sohag in the two seasons and El- Fayoum in the second season compared to the other environments. Assuit location produced the lowest cotton yield.

Sohag location in the two season and Assuit in the first season produced the highest values of fiber length and length uniformity ratio. The lowest value of fiber length was reported at Bani- Suef in the second season. El-Fayoum location gave the highest value of fiber strength in the first season. Bani-Suef and Assuit locations recorded the best values of micronaire reading in the two seasons also, El-Fayoum and sohag recorded the best values in the first season. These results were in agreement with those obtained by Hassan et al. (2006) and (2012), Nour et al. (2012), Abd El-Salam et al. (2014) and Shaker (2017).

Table 2. Effect of environments on traits of four Egyptian cotton genotypes.

\begin{tabular}{|c|c|c|c|c|c|c|c|c|c|}
\hline \multirow{2}{*}{ Location } & \multicolumn{2}{|c|}{ El-Fayoum } & \multicolumn{2}{|c|}{ Bani-Suef } & \multicolumn{2}{c|}{ Assiut } & \multicolumn{2}{c|}{ Sohag } & \multirow{2}{*}{$\begin{array}{c}\text { LSD } \\
\text { (0.01) }\end{array}$} \\
\cline { 1 - 9 } Year & Y1 & Y2 & Y1 & Y2 & Y1 & Y2 & Y1 & Y2 & \\
\hline SCY/kf & 8.11 & 8.49 & 11.34 & 8.14 & 6.11 & 5.45 & 9.25 & 12.49 & 1.55 \\
\hline LY/kf & 10.43 & 10.98 & 13.95 & 10.90 & 7.44 & 6.74 & 11.64 & 15.41 & 2.00 \\
\hline BW & 2.19 & 2.75 & 2.58 & 2.51 & 2.70 & 2.87 & 2.66 & 2.67 & 0.18 \\
\hline LP & 40.85 & 41.06 & 39.12 & 42.21 & 38.60 & 39.18 & 39.96 & 39.10 & 1.20 \\
\hline SI & 8.21 & 9.33 & 8.99 & 7.72 & 8.97 & 7.87 & 9.30 & 9.73 & 0.67 \\
\hline LI & 5.68 & 6.50 & 5.78 & 5.64 & 5.65 & 5.07 & 6.19 & 6.24 & 0.54 \\
FL & 28.73 & 28.58 & 28.69 & 27.59 & 30.15 & 28.76 & 30.26 & 31.28 & 1.26 \\
LUR & 83.26 & 82.24 & 83.16 & 82.16 & 84.04 & 81.84 & 83.71 & 83.76 & 1.74 \\
FS & 39.23 & 36.77 & 38.05 & 35.12 & 37.64 & 36.04 & 36.59 & 37.64 & 1.50 \\
MR & 4.06 & 4.34 & 3.77 & 3.74 & 3.81 & 3.82 & 4.03 & 4.36 & 0.35 \\
\hline
\end{tabular}

Y1= 2016 and Y2= 2017

\section{Cotton varietal differences:}

Data in table (3). showed the effect of different cotton genotypes on yield and its components and fiber properties. Genotypes were significantly different with regard to all studied traits except boll weight. The promising line CB 58× G.90 as a potential substitute for G.90 and G.95, exceeded significantly G.90 in seed cotton yield by $0.91 \mathrm{k} / \mathrm{f}(11 \%)$ and $\mathrm{G} .95$ by $1.296 \mathrm{k} / \mathrm{f}(16 \%)$. Also, the promising line CB $58 \mathrm{x}$ 
G.90 produced significantly higher lint cotton yield and exceeded significantly G.90 by $1.22 \mathrm{k} / \mathrm{f}(12 \%)$ and $\mathrm{G} .95$ by $1.4 \mathrm{k} / \mathrm{f}(14 \%)$ but, it equaled significantly the promising line $[((\mathrm{G} .83 \times$ G. 80$) \times$ G. 89$) \times$ Australian $]$. The promising line $[((G .83 \times$ G. 80) $\times$ G. 89) $\times$ Australian] surpassed all genotypes for lint percentage but, the promising line CB $58 \times$ G.90 recorded favorable value (39.62 \%) for this trait. The commercial cultivars Giza 90 and Giza 95 recorded the highest values for seed index and lint index traits.

These results confirm the findings of Hassan et al. (2006), (2012) and (2014), Nour et al. (2012), Abd El-Salam et al. (2014), and El-Ganayny (2017).

Table 3. The differences among genotypes for yield components, fiber quality and chemical treatments averaged at six environments.

\begin{tabular}{|c|c|c|c|c|c|c|c|c|c|c|}
\hline Genotype & SCY/kf & LY/kf & BW & LP & SI & LI & FL & LUR & FS & MR \\
\hline Giza 90 & 8.37 & 10.32 & 2.66 & 39.12 & 9.07 & 5.82 & 29.22 & 83.36 & 37.72 & 3.94 \\
\hline Giza 95 & 7.99 & 10.14 & 2.63 & 40.25 & 8.95 & 6.04 & 29.72 & 83.20 & 37.76 & 3.98 \\
\hline $\begin{array}{l}\text { [((G. 83 x G. 80) } \\
\text { x G. 89) x Aus. }]\end{array}$ & 9.04 & 11.74 & 2.58 & 41.05 & 8.52 & 5.94 & 28.93 & 82.58 & 37.20 & 3.89 \\
\hline CB58XG90 & 9.28 & 11.54 & 2.59 & 39.62 & 8.52 & 5.58 & 29.15 & 82.94 & 35.85 & 4.14 \\
\hline LSD 0.01 & 0.60 & 0.77 & NS & 0.47 & 0.51 & 0.37 & 0.44 & 0.61 & 0.53 & 0.12 \\
\hline
\end{tabular}

Note: NS= non significant.

With respect to fiber properties, results cleared that the commercial cultivar G.95 produced higher fiber length $(\mathrm{mm})$, length uniformity ratio, fiber strength and micronaire reading. It also exceeded the promising line CB $58 \times$ G 90 in most fiber properties and the promising line $[((G .83 \times$ G. 80) $\times$ G. 89) $\times$ Australian] in fiber length and length uniformity ratio. These results confirm the findings of Hassan et al. (2006 and 2012)

\section{Effect of the interaction between cotton genotypes and growing environments on the studied traits:}

Data in table (4) showed that the genotypes $\times$ environments interactions were significant for all traits except boll weight, seed index, lint index. Comparing the promising line CB 58 x Giza 90 as an expected substitute for the commercial cultivars Giza 90 and G.95 at most environments, it surpassed both of them for seed cotton yield in El- Fayoum, Bani- Suef and Sohag in the first season and Bani-Suef, Assuit and Sohag in the second season. Also, the promising line CB $58 \times$ Giza 90 produced the highest values of lint yield compared with G.90 and G.95 at El- Fayoum, Assuit and Sohag in the second season while, it surpassed G. 90 at Sohag in the first season also, it surpassed G.95 at Bani- Suef in the two seasons and El- Fayoum in the first season. The commercial cultivar G.95 recorded the highest lint percentage and did not significantly surpass the two promising lines at Bani- Suef in the second season and the promising line [(G. $83 \times$ G. 80) x G. 89] x Australian only in two seasons. But, the promising line CB $58 \times$ Giza 90 recorded the highest values compared to G.90 at all 
environments in the second season. These results agreed with those of Nour et al. (2012), Abd El-Salam et al. (2014), El-Ganayny (2017) and Shaker (2017).

Table 4. Effect of the interaction between cotton genotypes and environments for the two seasons on all studied traits.

\begin{tabular}{|c|c|c|c|c|c|c|c|c|c|c|}
\hline Location & \multicolumn{2}{|c|}{ El-Fayoum } & \multicolumn{2}{|c|}{ Bani-Suef } & \multicolumn{2}{|c|}{ Assiut } & \multicolumn{2}{|c|}{ Sohag } & \multirow{2}{*}{$\begin{array}{l}\text { LSD } \\
0.05\end{array}$} & \multirow{2}{*}{$\begin{array}{l}\text { LSD } \\
0.01\end{array}$} \\
\hline Year & Y1 & $\mathrm{Y} 2$ & Y1 & $\mathrm{Y} 2$ & Y1 & $\mathrm{Y} 2$ & $\mathrm{Y1}$ & $\mathrm{Y} 2$ & & \\
\hline & & & & SCY/kf & & & & & \multirow{6}{*}{-} & \multirow{6}{*}{1.70} \\
\hline G 90 & 7.42 & 8.50 & 11.43 & 8.15 & 6.10 & 4.51 & 8.52 & 12.37 & & \\
\hline G 95 & 7.68 & 8.17 & 10.29 & 7.14 & 5.76 & 4.84 & 9.89 & 10.18 & & \\
\hline$[((G .83 \times$ G. 80) x G. 89) x & & & & & & & & & & \\
\hline Aus.] & 7.91 & 9.68 & 11.24 & 8.42 & 6.88 & 5.84 & 8.42 & 13.95 & & \\
\hline CB58XG90 & 9.42 & 7.62 & 12.41 & 8.85 & 5.73 & 6.60 & 10.17 & 13.47 & & \\
\hline & & & & $\mathrm{LY} / \mathrm{kf}$ & & & & & \multirow{5}{*}{ - } & \\
\hline G 90 & 9.37 & 10.73 & 14.16 & 10.49 & 7.28 & 5.42 & 10.48 & 14.65 & & \multirow{4}{*}{2.18} \\
\hline G 95 & 9.83 & 10.55 & 12.96 & 9.60 & 7.07 & 5.97 & 12.56 & 12.60 & & \\
\hline $\begin{array}{l}{[((G .83 \times \text { G. 80) x G. 89) X }} \\
\text { Aus. }]\end{array}$ & 10.51 & 12.77 & 14.29 & 11.62 & 8.55 & 7.27 & 10.96 & 1793 & & \\
\hline $\begin{array}{ll}\text { CB58XG90 } \\
\end{array}$ & 12.01 & 9.86 & 14.39 & 11.91 & 6.87 & 8.30 & 12.57 & 16.45 & & \\
\hline & & & & BW & & & & & \multirow{6}{*}{ NS } & \\
\hline G 90 & 2.08 & 2.90 & 2.70 & 2.53 & 2.66 & 2.96 & 2.53 & 2.94 & & \multirow{5}{*}{ NS } \\
\hline G 95 & 2.27 & 2.77 & 2.58 & 2.52 & 2.73 & 2.93 & 2.69 & 2.59 & & \\
\hline$[((G .83 \times$ G. 80$) \times$ G. 89$) \times$ & & & & & & & & & & \\
\hline Aus.] & 2.17 & 2.68 & 2.43 & 2.53 & 2.73 & 2.87 & 2.71 & 2.49 & & \\
\hline CB58XG90 & 2.26 & 2.65 & 2.60 & 2.46 & 2.70 & 2.72 & 2.73 & 2.64 & & \\
\hline & & & & $\mathrm{LP}$ & & & & & & \\
\hline G 90 & 40.10 & 40.05 & 39.33 & 40.92 & 37.88 & 38.10 & 39.03 & 37.59 & & \\
\hline G95 & 40.63 & 40.96 & 39.98 & 42.70 & 39.00 & 39.21 & 40.28 & 39.29 & & 1.33 \\
\hline$[((G .83 \times$ G. 80) $\times$ G. 89) X & & & & & & & & & & \\
\hline Aus.] & 42.20 & 42.13 & 40.38 & 42.54 & 39.45 & 39.55 & 41.33 & 40.79 & & \\
\hline CB58XG90 & 40.48 & 41.09 & 36.80 & 42.71 & 38.08 & 39.85 & 39.23 & 38.75 & & \\
\hline & & & & SI & & & & & & \\
\hline G 90 & 7.84 & 9.46 & 9.41 & 8.01 & 9.68 & 8.56 & 9.44 & 10.14 & & \\
\hline G95 & 8.83 & 9.86 & 8.69 & 7.99 & 8.63 & 7.76 & 9.65 & 10.22 & NS & NS \\
\hline$[((\mathrm{G} .83 \times \mathrm{G} .80) \times \mathrm{G} .89) \times$ & & & & & & & & & & \\
\hline Aus.] & 8.12 & 9.55 & 8.70 & 7.38 & 8.75 & 7.52 & 9.00 & 9.17 & & \\
\hline CB58XG90 & 8.07 & 8.46 & 9.16 & 7.51 & 8.83 & 7.65 & 9.11 & 9.38 & & \\
\hline & & & & LI & & & & & & \\
\hline G 90 & 5.24 & 6.32 & 6.10 & 5.56 & 5.91 & 5.27 & 6.04 & 6.11 & & \\
\hline G 95 & 6.04 & 6.84 & 5.80 & 5.95 & 5.53 & 5.01 & 6.50 & 6.61 & NS & NS \\
\hline$[((G .83 \times$ G. 80) $\times$ G. 89) $\times$ & & & & & & & & & & \\
\hline Aus.] & 5.93 & 6.95 & 5.89 & 5.47 & 5.70 & 4.93 & 6.34 & 6.32 & & \\
\hline CB58XG90 & 5.51 & 5.90 & 5.33 & 5.59 & 5.45 & 5.07 & 5.89 & 5.93 & & \\
\hline & & & & $\mathrm{FL} .(\mathrm{mm})$ & & & & & & \\
\hline G 90 & 28.43 & 27.20 & 28.80 & 27.33 & 30.55 & 29.58 & 30.85 & 31.03 & & \\
\hline G95 & 29.08 & 30.05 & 29.15 & 27.90 & 30.35 & 29.15 & 30.38 & 31.68 & - & 1.26 \\
\hline$[((G .83 \times$ G. 80) $\times$ G. 89) $\times$ & & & & & & & & & & \\
\hline Aus.] & 28.45 & 28.40 & 28.78 & 27.20 & 30.10 & 27.73 & 29.90 & 30.93 & & \\
\hline CB58XG90 & 28.95 & 28.68 & 28.05 & 27.93 & 29.60 & 28.58 & 29.93 & 31.50 & & \\
\hline & & & & LUR $\%$ & & & & & & \\
\hline G 90 & 84.15 & 82.55 & 83.98 & 81.73 & 84.03 & 81.80 & 84.08 & 84.60 & & \\
\hline G95 & 82.68 & 82.68 & 83.03 & 82.45 & 84.13 & 82.00 & 84.38 & 84.25 & 1.31 & NS \\
\hline$[((G .83 \times$ G. 80) x G. 89) X & & & & & & & & & & \\
\hline Aus.] & 83.23 & 81.85 & 83.03 & 80.95 & 84.08 & 81.03 & 83.43 & 83.10 & & \\
\hline CB58XG90 & 83.00 & 81.90 & 82.60 & 83.50 & 83.95 & 82.55 & 82.98 & 83.08 & & \\
\hline & & & & FS.g/tex & & & & & & \\
\hline G 90 & 39.20 & 36.50 & 39.23 & 34.30 & 42.23 & 35.25 & 36.60 & 38.45 & & \\
\hline G95 & 40.45 & 37.70 & 35.75 & 36.45 & 35.30 & 36.55 & 41.50 & 38.35 & & 1.50 \\
\hline$[((G .83 \times$ G. 80$) \times$ G. 89) X & & & & & & & & & - & \\
\hline Aus.] & 42.93 & 36.13 & 41.23 & 34.58 & 36.50 & 35.85 & 34.20 & 36.25 & & \\
\hline CB58XG90 & 34.33 & 36.75 & 36.00 & 35.15 & 36.55 & 36.50 & 34.05 & 37.50 & & \\
\hline & & & & MR & & & & & & \\
\hline G 90 & 4.13 & 4.23 & 3.85 & 3.73 & 3.70 & 3.60 & 3.98 & 4.33 & & \\
\hline G 95 & 4.05 & 4.35 & 3.73 & 3.70 & 3.75 & 3.95 & 4.00 & 4.35 & 0.26 & NS \\
\hline$[((G .83 \times$ G. 80) x G. 89) X & & & & & & & & & & \\
\hline Aus.] & 3.70 & 4.38 & 3.70 & 3.60 & 3.93 & 3.78 & 3.80 & 4.28 & & \\
\hline CB58XG90 & 4.35 & 4.40 & 3.80 & 3.93 & 3.85 & 3.95 & 4.35 & 4.48 & & \\
\hline
\end{tabular}


With respect to fiber properties, the commercial cultivar G.95 recorded the highest fiber length shared with significantly the remaining genotypes at Sohag in the second season also, shared with significantly the cultivar G.90 at Sohag and Assuit in the first season for this trait. All genotypes recorded the highest length uniformity ratio at Assuit in first season while, the cultivars Giza 90 and Giza 95 recorded the highest values at Sohag in the two seasons. The promising line line $[((G .83 \times$ G. 80) $x$ G. 89) $x$ Australian] recorded the highest fiber strength at El-Fayoum in the first season. Bani- Suef and Assuit locations recorded the best micronaire reading for most genotypes. Similar results were reported by Nour et al. (2012), El-Ganayny (2014) and Shaker (2017).

\section{Stability and adaptability}

The results in Table (5) indicated that the mean performance of seed cotton yield/fad. for lines line [((G. 83 x G. 80) x G. 89) x Australian] and CB 58 x Giza 90 differed significantly from the two commercial cultivars. The highest values were given by the two lines which produced more than $9.00 \mathrm{k} /$ fad. for seed cotton yield. These genotypes had the values of regression coefficient which did not differ significantly from unity $(b i=1)$ but, values of deviation from regression $\left(S^{2} d\right)$ differed significantly from zero $\left(S^{2} d \neq 0\right)$ so, they are considered unstable. However, the cultivar G.90 had higher mean performance $(\overline{\mathcal{X}}=$ high), regression coefficient equal unity $(\mathrm{bi}=1)$ and deviation from regression equal zero $\left(S^{2} d i=0\right)$ hence, it is considered stable cultivar according to Eberhart and Russel (1966).

Table 5. Averages of genotypes and estimates of stability parameters for seed cotton yield over 8 environments.

\begin{tabular}{|c|c|c|c|}
\hline genotype & $\begin{array}{c}\text { Mean } \\
(\mathrm{x})\end{array}$ & $\begin{array}{c}\text { Regression coefficient } \\
\left(\mathrm{b}_{\mathrm{i}}\right)\end{array}$ & $\begin{array}{c}\text { Deviation from regression } \\
\left(\mathrm{S}^{2} \mathrm{~d}\right)\end{array}$ \\
\hline Giza 90 & 8.37 & 1.0699 & -0.1411 \\
\hline Giza 95 & 7.99 & 0.8090 & 0.2757 \\
\hline [((G. 83 $\times$ G. 80$) \times$ G. 89$) \times$ Aus. $]$ & 9.04 & 1.0341 & $0.3517^{*}$ \\
\hline CB58XG90 & 9.28 & 1.0870 & $0.3833^{*}$ \\
\hline Grand Mean & \multicolumn{3}{|c|}{0.67} \\
\hline LSD : 0.01 & \multicolumn{3}{|c|}{0.60} \\
\hline
\end{tabular}

* Significant at the 0.05 probability level.

The genotypes G.90, [((G. 83 x G. 80) x G. 89) x Australian] and CB $58 \times$ Giza 90 had high mean performance and regression coefficient equal unity hence, they are generally adaptable for all environments also, G.95 behaved as less sensitive to any change in environments and would be more adapted to low ( poor- yielding environments) because, it had ( $\mathrm{bi}$ ) blow one $\mathrm{bi}=0.8090$ therefore, increasing the specificity of adaptability to low yielding environments, Finally and Wilkinson (1963) 
considered the genotypes which $(\mathrm{bi}<1)$ behave as less sensitive to any change in environments to be more adapted to low (poor) yielding environments. They further pointed out that genotypes having ( $\mathrm{bi}>1$ ) would show more sensitivity to environmental changes and adaptability to high (rich) yielding environments (Table 5). Also, genotypes having $b i=1$ and $S^{2} d i=0$ would indicate average stability and when this is associated with high mean yield, such genotypes would have good general adaptability. Fig. (1) shows mean seed cotton yield of genotypes plotted against their regression coefficient. The genotypes Giza 90, [(G.83 x G.80) x G.89] x Aus. and CB $58 \times$ Giza 90 had closer to one regression coefficient with average seed cotton yield and could be considered widely adapted to most environments. Such stable performance is a desirable attribute of cultivars, particularly for Egypt and other countries, where environmental variations are high and unpredictable.

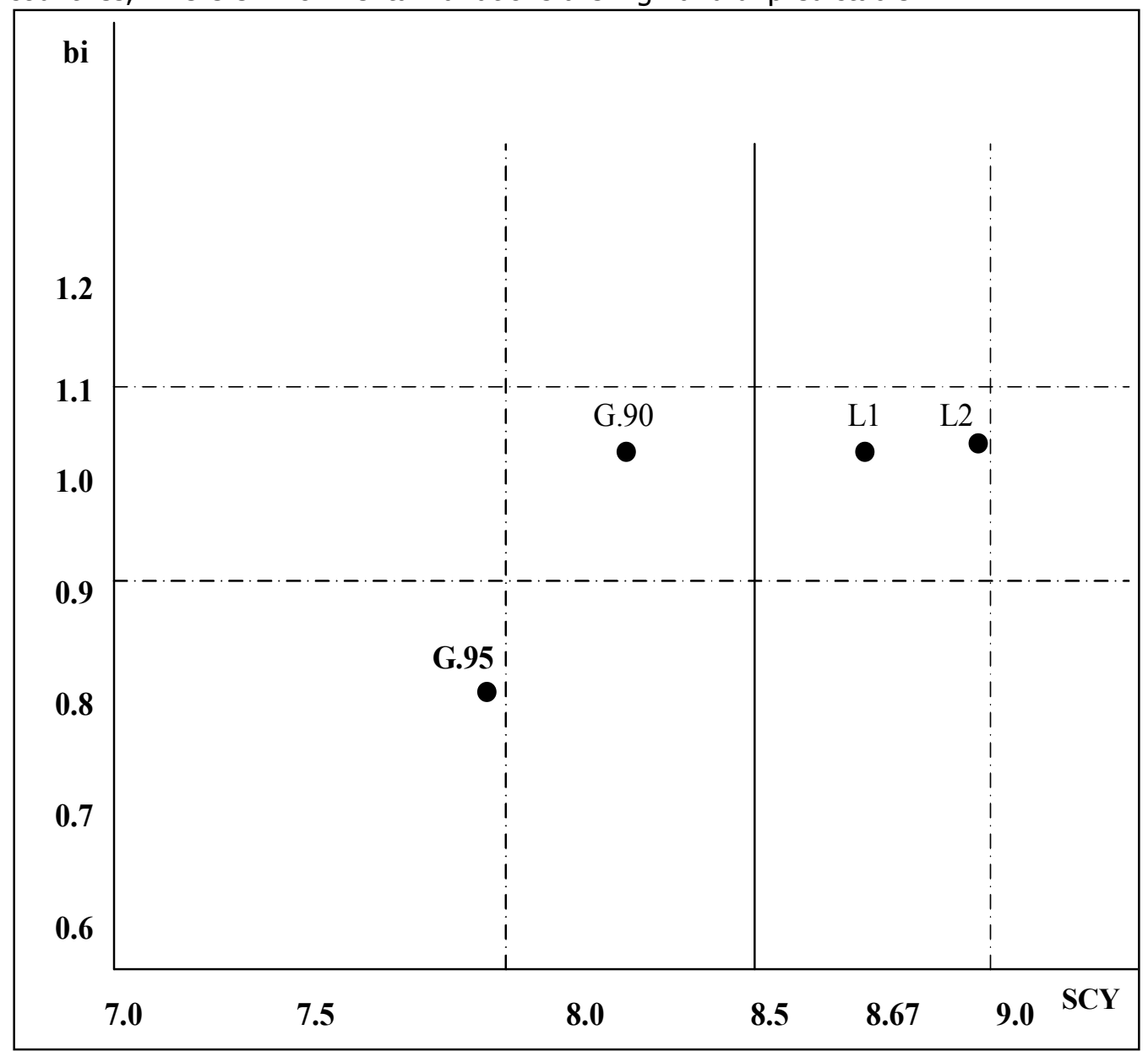

Fig. 1. Mean seed cotton yield of genotypes plotted against their regression coefeicint. $\mathrm{L} 1=[((\mathrm{G} .83 \times$ G. 80) $\times$ G. 89) $\times$ Aus. $]$ $\mathrm{L} 2=\mathrm{CB} 58 \times \mathrm{G} .90$ 


\section{CONCLUSION}

The promising line CB $58 \times$ G. 90 produced higher seed cotton and lint cotton yields $(\mathrm{k} / \mathrm{f})$ at most locations. It also equalized with commercial cultivars in fiber properties at Sohag location. The cultivar Giza 95 surpassed most genotypes in fiber properties. The cultivar Giza 90 is considered stable across a wide range of environments. The cultivar Giza 95 is less sensitive to any change in environment and would be more adapted to low (poor- yielding environments). The genotype Giza 90 and the two lines had general adaptability for all environments. These results generally, were in harmony with the findings of other authors.

As a general conclusion, it appears that there is a need to continue evaluating cotton genotypes, whether old or newly developed ones by growing them at several locations over an adequate number of years before recommending a given variety to a specific location.

\section{REFERENCES}

1. Abd El-Salam, M.E., S.A. Shaker, A.E.I. Darwesh and S.S.M. Badr 2014. Evaluation of some cotton lines under different environmental conditions. J. Agric. Res. Kafrelsheikh Univ., Egypt 40 (4): $804-818$.

2. A.S.T.M. 1986. American Society for Testing Materials, D-4605. U.S.A.

3. A.S.T.M. 1998. American Society for Testing Materials, D-1776, U.S.A.

4. Badr, S. S. M. 2003. Comparative evaluation of promising hybrid Giza 84 (Giza 74 $\times$ Giza 86 ) and extra long staple cotton varieties grown in North Delta. Egypt J. Agric. Res., 81(3): 1149-1169.

5. Bailey, N. T. 1994. Statical Methods in Biolojy. Third Ed. Cambridge University press, Cambridge, England.

6. Eberhart, S.A. and W.A. Russell. 1966. Stability parameters for comparing varieties. Crop Sci. 6: 36-40.

7. El-Ganayny, H.A.E. 2017. Evaluation of some Egyptian cotton genotypes in different locations different in type of soils and quality of irrigation water. Ph. D. Thesis, Fac. Of Agric., Tanta Univ., Egypt.

8. Finlay, K.W. and Wilkinson, G.N. 1963. The analysis of adaptation in plant breeding programme. Asut. J. Agric. Res., 14: 742-754.

9. Gibely, R.H.A., Aziza M. Soultan, H. A. El-Hoseiny and E. A. Amer. 2015. Assessment of genetic variability and stability for some cotton genotypes. Egypt. J. Plant Breed. 19(6):1783 - 1801.

10. Gul, S.; N.U. Khan; S. Batool; M. Munir; M. Sajid; A.A. Khakwani; S.H. Ghaloo; Z.A. Soomro and S.F. Kazni. 2014. Genotype by environment interaction and 
association of morpho-yield variables in upland cotton. The Journal of Animal \& Plant Sciences, 24(1): 262-271.

11. Hassan, I.S.M. 2006. Comparative evaluation of two promising hybrids of cotton and three long staple commercial cultivars grown at South and middle Delta. Egypt. J. of Appl. Sci., 21(7): 128-142.

12. Hassan, I.S.M.; S.S.M. Badr and S.A.M. Hassan. 2012. Study of phenotypic stability of some Egyptian cotton genotypes under different environments. Egypt. J. of Appl. Sci., 27 (6): 298-315.

13. Hassan I.S.M, S.S.M. Badr, S.M.Seyam, L.M.A.Abd El-Rahman And H.B.I. AbouTour. 2014. Evaluation of some new promising strains and Egyptian cotton commercial cultivars grown at different locations. Egypt. J. Agric. Res., 91(3): 1025-1039.

14. Mcintosh, M.S. 1983. Analysis of combined experiments. Agron. J., 75: 153 155.

15. Nour O.D., Rokaya M. Hasaan, I.S.M. Hassan and M.S. Saleh. 2012. Evaluation of The promising strain [G.83 (G. $75 \times 5844)] \times$ G.80 in comparison with the two Egyptian cotton cultivars Giza 80 and Giza 90 grown under different environments. Egypt. J. of Appl. Sci., 27 (12): 461-476.

16. Pretorius, M.M.; J. Allenunn and M.F. Smith. 2015. Use of AMMI model to analyse cultivar-environment interaction in cotton under irrigation in South Africa. African J. Agric., 2(2): 75-80.

17. Rahoumah, M.R.A., A.M.R. Abd El- Bary, H.M. Hamoud and W.M.B. Yeha. 2008. Assessment of genetic diversity and stability for yield traits of some Egyptian long- staple cotton genotypes. Egypt. J. Agric. Res., 86 (4) : 1447-1462.

18. Senedcor, G. W. and W. G. Cochran. 1989. Statistical Methods, 8th ed. Iowa State Univ. Press, U. S. A.

19. Shaker S. A. 2017. Evaluation and stability analyses of some Egyptian cotton cultivars. Egypt. J. Plant Breed. 21(5):665 - 683.

20. Steel, R. G. M. and J.H. Torrie. 1980. Principles and procedures of statistics. Second Edit Mc Graw Hill Book Co. New York, U.S.A. 


\title{
تقييم سلاله القطن المبشرة CB 58 x Giza 90 بالوجه القبلي
}

\author{
شاكر عبد العزيز شاكر و حمدي بيومي أبو طور \\ معهر بحوث القطن - مركز البحوث الزر اعية - الجيزة
}

أجرى هذا البحث لتقييم الـ سلالة المبشرة CB 58 x Giza 90 مقار نة بالصنفين المنزر عين جيزة

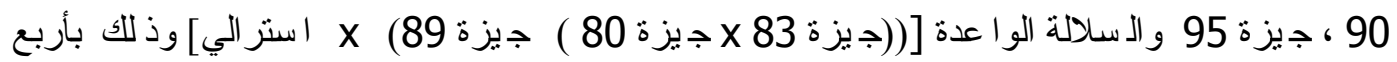

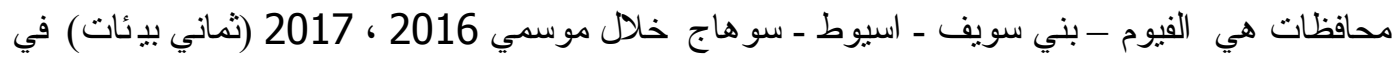

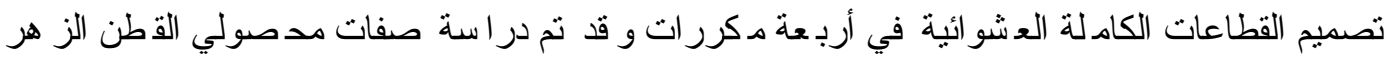

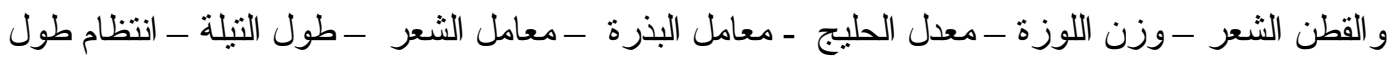

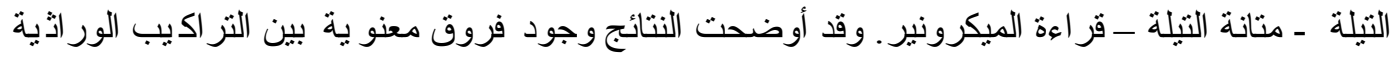

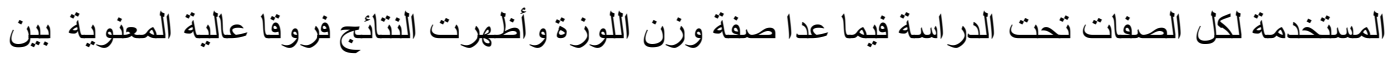

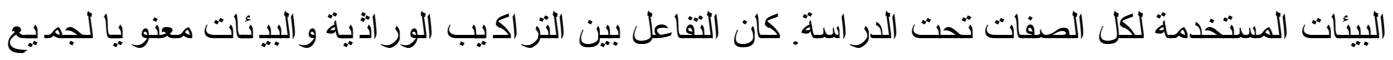

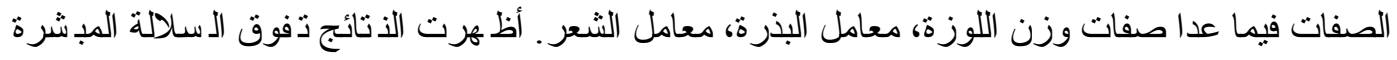
على الأصناف التجارية في صفات مدصولي القطن الز هر و الشعر (فنطار /فدان)

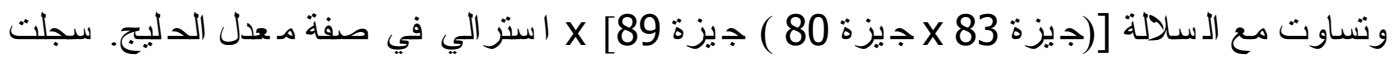

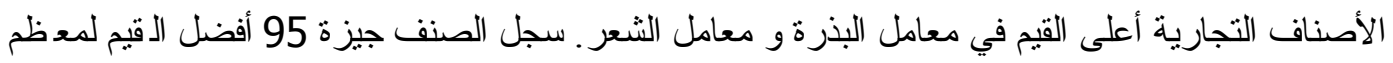

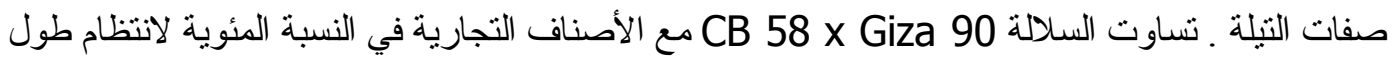

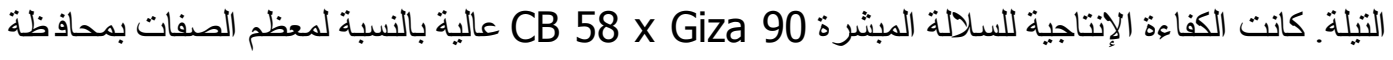

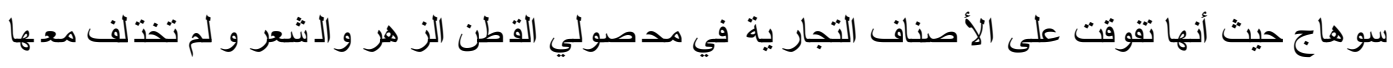

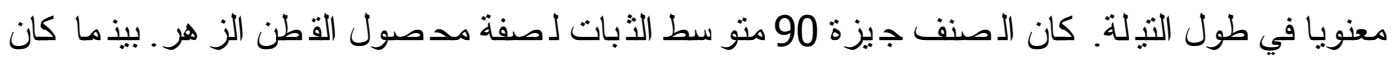

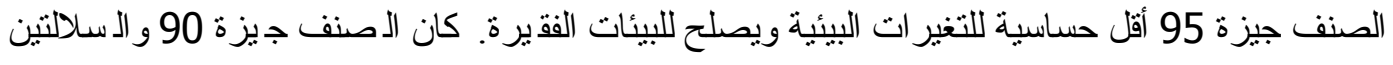
المبشرنين أكثر أقلمه مع كل البيئات تحت الدر اسة. 